\title{
Criteria for Assessing the Extent of Tumor Regression in Malignant Tumors of the Rectum
}

\section{Azimov EH and Gadirova EM*}

Chemical Sciences, Ecological Chemistry Department, Baku State University, Baku, Azerbaijan

\begin{abstract}
The purpose of our study has been studying criteria for evaluating regression of malignant rectal tumors as a result of neoadjuvant therapy. All materials removed during surgery were analyzed using visual-microscopic and microscopic examination.
\end{abstract}

Keywords: Malignant tumors; Tumor regression; Neoadjuvanttherapy; Fibrosis; Radioresistant tumor; satisfactory; Unsatisfactory regression

\section{Introduction}

The purpose of the research is to study the criteria for evaluating the regression of malignant rectal tumors after neoadjuvant therapy. 103 patients with the established diagnosis of the rectal cancer were involved in a research. To assess the extent of tumor regression, the Rectal Cancer Regression Grade (Wheeler) scale was used. All materials removed during surgery were analyzed using visual-microscopic and microscopic examination.

\section{Materials and Methods}

We examined 103 patients diagnosed with cancer of various parts of the rectum. Observations were carried out between 2010 and 2015 on the basis of Clinical Hospital No.1 (Azerbaijan Medical University), as well as in the ELMED Medical Center. Patients were divided into 2 groups: 1) patients who underwent total open mesorectumectomy (OSTM) - $(\mathrm{n}=56)$; 2) patients to whom TME was performed by laparoscopic method (LTME) - $(\mathrm{n}=47)$.

Cancer of the rectum is one of the most common cancer diseases. According to the World Health Organization, the rate of increase in the incidence of rectal cancer, exceeded the threshold of 1 million cases per year [1]. Early development of local recurrences and distant metastases is a serious problem facing surgeons involved in the treatment of rectal diseases. Despite the fact that, the abdominal perineal extirpation, proposed for rectal cancer by Miles, opened a new era in the treatment of rectal cancer, the introduction of radio- and chemotherapy enabled the development of new approaches to solving this problem [2]

At present, considerable progress is being made in the treatment of rectal cancer, associated with a thorough study of the surgical anatomy of the small pelvis, features of the lymph drainage and the inclusion of a therapeutic arsenal of combined regimens.

The introduction of total mesorectal excision (TME) into practice, which revolutionized the treatment of rectal cancer, led to a significant reduction in local relapses (up to 6-10\%) [3]. Despite this, the outcomes of treatment of rectal cancer both from the point of view of the development of local relapses and the appearance of distant metastases remain disappointing. Advances in the use of modern technologies (video endoscopic technologies), as well as the improvement of radiotherapy have led to the need to review many approaches to surgical intervention [4].

Isolated use of surgical methods of treatment is often associated with a high risk of local relapses. Pre-operative radiochemotherapy (neoadjuvanttherapy) is practically the only method that can prevent local relapses [5,6]. This therapy helps to reduce the size of the tumor, increasing its operability, creates conditions for sphinctersaving operations at low-lying tumors. In this regard, a prerequisite is the evaluation of the results of neoadjuvanttherapy with magnetic resonance tomography (MRT) [7,8]. The presence or absence of the effect of therapy, the study of the degree of tumor regression is of great importance for determining further treatment tactics [4,9]. The distribution of patients by age and sex is indicated in Table 1 . The distribution of patients by TNM is presented in Table 2 .

Depending on the stage of the disease, short (Swedish) and long (English) protocols for radiochemotherapy were administered to patients (Table 3). Similar therapy was performed among the patient in stages $\mathrm{T}_{1}$ and $\mathrm{T}_{2} \mathrm{~N}_{\mathrm{o}} \mathrm{M}_{\mathrm{o}}$ before surgery.

In order to assess the extent of tumor regression, the Rectal Cancer Regression Grade (Wheeler) scale was used. All materials removed during surgery were analyzed by visual-microscopic and microscopic examination [10].

\section{Results and Discussion}

At the first stage, the main method of treatment of rectum formations is surgical. If the tumor spreads transmurally, and there are metastases or suspicions in them in periorrectal lymph nodes, preoperative or postoperative radiotherapy is mandatoryin order to control the disease locally and to improve long-term outcomes, in addition to the operative intervention. Local recurrences have a negative impact on the prognosis of colorectal cancer. The main and most significant anatomical and biological factors influencing the risk of local relapse are the degree of tumor germination into the rectal wall, the presence of tumor cells in the lymph nodes, the circular border of resection (circumferentialresectionmargin-CRM), vascular and perineural invasion, the degree of differentiation and the location of the tumor $[2,11]$. In our opinion, from the standpoint of preventing the development of local relapses and distant metastases, as well as improving survival, preoperative radio (chemo) therapy is more expedient.

*Corresponding author: Gadirova EM, Chemical Sciences, Ecological Chemistry Department, Baku State University, Baku, Azerbaijan, Tel: +994124344870; E-mail: elmina2010@mail.ru

Received July 31, 2017; Accepted August 07, 2017; Published August 11, 2017

Citation: Azimov EH, Gadirova EM (2017) Criteria for Assessing the Extent of Tumor Regression in Malignant Tumors of the Rectum. Med Chem (Los Angeles) 7: 235-238. doi: 10.4172/2161-0444.1000462

Copyright: (c) 2017 Azimov EH, et al. This is an open-access article distributed under the terms of the Creative Commons Attribution License, which permits unrestricted use, distribution, and reproduction in any medium, provided the original author and source are credited. 


\begin{tabular}{|c|c|c|c|c|c|c|c|c|}
\hline \multirow{3}{*}{ Age (years) } & \multicolumn{4}{|c|}{ (LTME) $n=47$} & \multicolumn{4}{|c|}{ (OTME) n=56 } \\
\hline & The husband & The wife & The husband & The husband & The husband & The husband & The husband & The husband \\
\hline & abc & ab & $\%$ & $\%$ & $a b c$ & $a b c$ & $\%$ & $\%$ \\
\hline $20-29$ & 1 & - & 5 & - & - & 1 & - & 3.3 \\
\hline $30-39$ & 2 & 1 & 10 & 3.7 & 1 & 2 & 3.8 & 6.7 \\
\hline $40-49$ & 4 & 5 & 20 & 18.5 & 2 & 6 & 7.7 & 20 \\
\hline $50-59$ & 5 & 7 & 25 & 25.9 & 7 & 9 & 26.9 & 30 \\
\hline $60-69$ & 7 & 11 & 35 & 40.7 & 13 & 10 & 50 & 33.3 \\
\hline $70>$ & 1 & 3 & 5 & 11.1 & 3 & 2 & 11.5 & 6.7 \\
\hline All & 20 & 27 & 42.6 & 57.4 & 26 & 30 & 46.4 & 53.6 \\
\hline
\end{tabular}

Table 1: Distribution of patients by age and sex.

\begin{tabular}{|c|c|c|c|c|c|}
\hline \multirow{2}{*}{ TNM } & \multirow{2}{*}{ Localization of the formation (part of the rectum) } & \multicolumn{2}{|c|}{ Laparoscopic TME $(n=47)$} & \multicolumn{2}{|c|}{ Open TME $(n=56)$} \\
\hline & & Aбc. number & $\%$ & Абс. number & $\%$ \\
\hline \multirow{3}{*}{$\mathrm{T}_{1} \mathrm{~N}_{0} \mathrm{M}_{0}$} & Upper & 2 & 4.25 & 1 & 1.78 \\
\hline & Average & 1 & 2.12 & 2 & 3.57 \\
\hline & Bottom & - & - & 2 & 3.57 \\
\hline \multirow{3}{*}{$\mathrm{T}_{1} \mathrm{~N}_{1} \mathrm{M}_{0}$} & Upper & 1 & 2.12 & 1 & 1.78 \\
\hline & Average & 1 & 2.12 & 2 & 3.57 \\
\hline & Bottom & - & - & 1 & 1.78 \\
\hline \multirow{3}{*}{$\mathrm{T}_{2} \mathrm{~N}_{0} \mathrm{M}_{0}$} & Upper & 2 & 4.25 & 3 & 3.35 \\
\hline & Average & 2 & 4.25 & 2 & 3.57 \\
\hline & Bottom & 3 & 6.38 & 2 & 3.57 \\
\hline \multirow{3}{*}{$\mathrm{T}_{1} \mathrm{~N}_{1} \mathrm{M}_{0}$} & Upper & 1 & 2.12 & - & - \\
\hline & Average & 3 & 6.38 & 4 & 7.14 \\
\hline & Bottom & 1 & 2.12 & 2 & 3.57 \\
\hline \multirow{3}{*}{$\mathrm{T}_{2} \mathrm{~N}_{2} \mathrm{M}_{0}$} & Upper & 1 & 2.12 & 2 & 3.57 \\
\hline & Average & 2 & 4.25 & 3 & 5.35 \\
\hline & Bottom & 1 & 2.12 & 1 & 1.78 \\
\hline \multirow{3}{*}{$\mathrm{T}_{3} \mathrm{~N}_{0} \mathrm{M}_{0}$} & Upper & 3 & 6.38 & 2 & 3.57 \\
\hline & Average & 5 & 10.63 & 3 & 5.35 \\
\hline & Bottom & 2 & 4.25 & 3 & 5.35 \\
\hline \multirow{3}{*}{$\mathrm{T}_{3} \mathrm{~N}_{1-2} \mathrm{M}_{0}$} & Upper & 5 & 10.63 & 4 & 7.14 \\
\hline & Average & 2 & 4.25 & 2 & 3.57 \\
\hline & Bottom & 2 & 4.25 & 3 & 5.35 \\
\hline \multirow{3}{*}{$\mathrm{T}_{4} \mathrm{~N}_{1} \mathrm{M}_{0}$} & Upper & 1 & 2.12 & - & - \\
\hline & Average & 1 & 2.12 & 1 & 1.78 \\
\hline & Bottom & 1 & 2.12 & 2 & 3.57 \\
\hline \multirow{3}{*}{$\mathrm{T}_{4} \mathrm{~N}_{2} \mathrm{M}_{0}$} & Upper & 1 & 2.12 & 2 & 3.57 \\
\hline & Average & 1 & 2.12 & 2 & 3.57 \\
\hline & Bottom & 2 & 4.25 & 4 & 7.14 \\
\hline
\end{tabular}

Table 2: Distribution of patients with malignant formations of various parts of the rectum by TNM.

\begin{tabular}{|c|c|c|c|c|c|c|}
\hline \multirow{2}{*}{ Stage on MRT } & \multirow{2}{*}{$\begin{array}{l}\text { Localization of the formation (part of the } \\
\text { rectum) }\end{array}$} & \multirow{2}{*}{ Protocol of the treatment } & \multicolumn{2}{|c|}{$\begin{array}{l}\text { Laparoscopic TME } \\
\qquad(n=35)\end{array}$} & \multicolumn{2}{|c|}{$\begin{array}{l}\text { Open TME } \\
(n=49)\end{array}$} \\
\hline & & & $\begin{array}{c}\text { Aбc. } \\
\text { number }\end{array}$ & $\%$ & Aбc.number & $\%$ \\
\hline \multirow{4}{*}{$\mathrm{T}_{1}-\mathrm{T}_{2} \mathrm{~N}_{0}$} & Upper & - & - & - & - & - \\
\hline & Average & Short & 1 & 2.85 & 1 & 2.04 \\
\hline & \multirow{2}{*}{ Bottom } & Short & - & - & - & - \\
\hline & & Long & 1 & 2.85 & - & - \\
\hline \multirow{4}{*}{$\begin{array}{c}\mathrm{T}_{1}-\mathrm{T}_{2} \\
\mathrm{~N}_{1}-\mathrm{N}_{2} \\
\text { Inside the mesorectum }\end{array}$} & Upper & Short & 1 & 2.85 & 1 & 2.04 \\
\hline & Average & Short & 2 & 5.71 & 4 & 8.16 \\
\hline & \multirow{2}{*}{ Bottom } & Short & 1 & 2.85 & 1 & 2.04 \\
\hline & & Long & - & - & 1 & 2.04 \\
\hline \multirow{3}{*}{$\begin{array}{c}\mathrm{T}_{1}-\mathrm{T}_{2} \\
\mathrm{~N}_{1}-\mathrm{N}_{2} \\
\text { Outside the mesorectum }\end{array}$} & Upper & Long & - & - & 1 & 2.04 \\
\hline & Average & Long & 2 & 5.71 & 2 & 4.08 \\
\hline & Bottom & Long & 1 & 2.85 & 2 & 4.08 \\
\hline \multirow{3}{*}{$\begin{array}{l}\mathrm{T}_{3} \mathrm{~N}_{0} \\
\text { (Negative circular margin of resection) }\end{array}$} & Upper & Short & 2 & 5.71 & 1 & 2.04 \\
\hline & Average & Short & 2 & 5.71 & 1 & 2.04 \\
\hline & Bottom & Long & 1 & 2.85 & 1 & 2.04 \\
\hline
\end{tabular}




\begin{tabular}{|c|c|c|c|c|c|c|}
\hline \multirow{3}{*}{$\begin{array}{l}\mathrm{T}_{3} \mathrm{~N}_{1}-\mathrm{N}_{2} \\
\text { Inside the mesorectum }\end{array}$} & Upper & Short & 3 & 8.57 & 2 & 4.08 \\
\hline & Average & Short & 2 & 5.71 & 1 & 2.04 \\
\hline & Bottom & Long & 1 & 2.85 & 2 & 4.08 \\
\hline \multirow{3}{*}{$\begin{array}{l}\qquad \mathrm{T}_{3} \mathrm{~N}_{1}-\mathrm{N}_{2} \\
\text { Ouside the mesorectum }\end{array}$} & Upper & Long & 2 & 5.71 & 2 & 4.08 \\
\hline & Average & Long & - & - & 1 & 2.04 \\
\hline & Bottom & Long & 1 & 2.85 & 1 & 2.04 \\
\hline \multirow{3}{*}{$\begin{array}{c}T_{3} \text { (Positive circular margin of resection), } \\
T_{4}\end{array}$} & Upper & Long & 3 & 8.57 & 3 & 6.12 \\
\hline & Average & Long & 5 & 14.28 & 5 & 10.2 \\
\hline & Bottom & Long & 4 & 11.42 & 8 & 16.32 \\
\hline
\end{tabular}

Table 3: Schemes of radiochemotherapy, conducted from patients with malignant rectum formations without distant metastases.

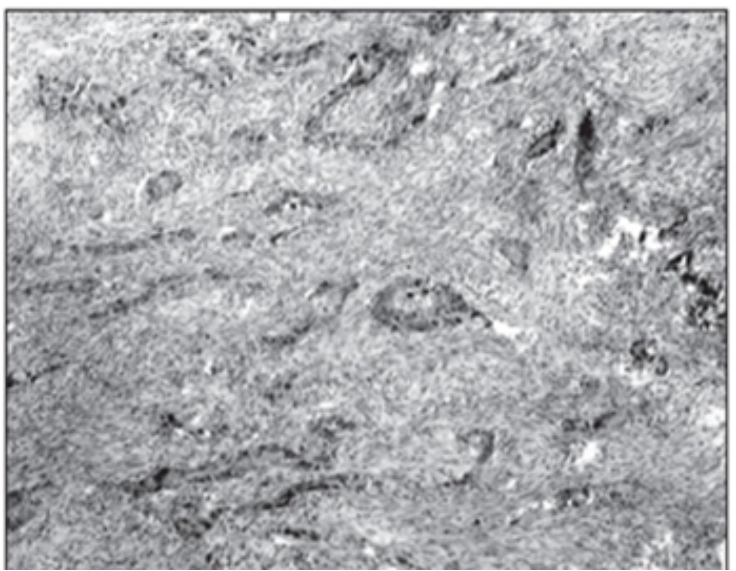

Figure 1: Pathomorphism of colorectal cancer, induced by neoadjuvant chemoradiotherapy. MR-tomogram of a tumor of a rectum in III stage $\left(\mathrm{T}_{2} \mathrm{~N}_{2} \mathrm{Mo}\right)$ before neoadjuvant therapy.

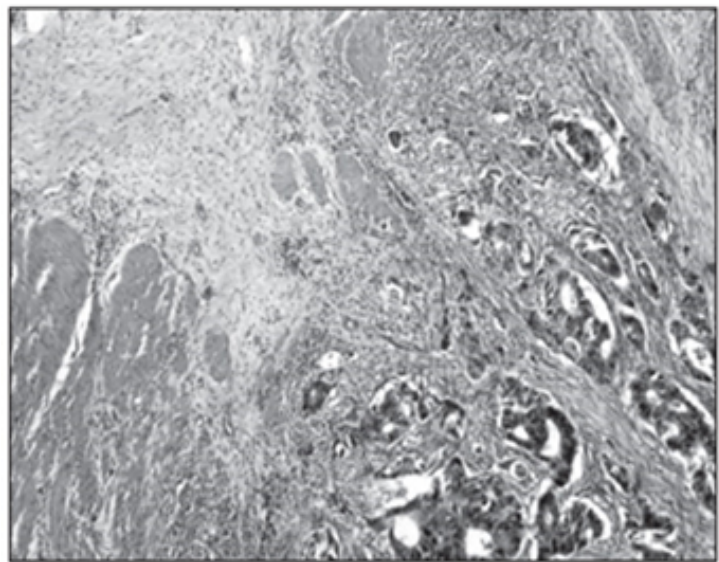

Figure 2: The same patient, MR-tomography after preoperative radiochemotherapy.

The results of our study suggest that preoperative radio (chemotherapy) therapy promotes macroscopic regression of the tumor, a decrease in the number of residual cells, and in some cases complete resorption of the tumor. In other cases, after treatment, there is practically no decrease in the size (radioresistance) of the tumor. The results were evaluated on the basis of preoperative magnetic resonance tomography (Figures 1 and 2).

Located in the lateral part of the mid-ampullar rectal section and the muscle layer that invaded the muscular layer, the tumor almost completely dissolved after radiochemotherapy and was not determined macroscopically. However, microscopic examination shows that even in the case when the tumor is not visually-macroscopically recorded, entities of adenocarcinoma and elements of fibrous tissue remain microscopically in it.

For correct microscopic evaluation of the remote material in both groups, we used the Rectal Cancer Regression Grade (Wheeler) scale. Of the 114 patients under observation, 95 received neoadjuvanttherapy. Under the influence of neoadjuvanttherapy, complete resorption of the tumor was noted in $18.94 \%$ of patients, in $69.47 \%$ partial, and in $11.57 \%$ of patients the tumor size did not change (radioresistant patients). Radio-resistant patients were not included in the study. The analysis was conducted for patients who had either complete or partial resorption of the tumor. Observations have shown that factors such as neoadjuvanttherapy, the degree of tumor differentiation, its stage and location, have a significant influence on tumor regression.

However, in some cases, the absence of a tumor response to therapy can not be explained by anything. In all probability, this process is affected by the biological properties of the tumor, as well as some completely unexplored characteristics of education. The extent of tumor spread to mesorectal tissue, the presence of tumor deposits, the circular margin of resection and the attachment of lymphovascular invasion are important factors affecting the regression of education [12].

It is logical that a higher incidence of regression will have a tumor in the mesorectum that does not show signs of lymphovascular and perineural invasion.

Table 4 shows the distribution of patients in the OTME and LTME groups, depending on the complete or partial response to neoadjuvant therapy.

When assessing the degree of regression in malignant tumors of the rectum, we took into account the following features. Regression of high degree - complete disappearance of tumor tissue (sterilization) or preservation of only a small entities of adenocarcinoma or increased fibrosis, satisfactory regression - increased fibrosis and macroscopic presence of residual tumor tissue, unsatisfactory regression - small fibrosis or its absence, macroscopically pronounced tumor process. The criteria for assessing the degree of tumor regression are presented in Table 5.

Our observations show that neoadjuvanttherapy causes significant histopathological changes in the most malignant tumor and surrounding tissue. When applying preoperative radiotherapy in tumor complexes, necrobiotic changes are clearly traced, leading to the complete death of a part of the cells.

As a result, necrotic structureless masses accumulate in the lumen of the cancer glands. The tumor complexes are surrounded by a marked inflammatory cell infiltrate. Tumor cells in the complexes are sharply dystrophic, acquire an ugly form. The boundaries between the tumor cells are erased. In places in the stroma there are sharply distrophed disjointed tumor cells that have lost the ability to form complexes. The wall of large arterial vessels is thickened, sclerotized. In venules 


\begin{tabular}{|c|c|c|c|c|c|c|}
\hline \multirow{2}{*}{$\begin{array}{c}\text { Response to } \\
\text { neoadjuvant } \\
\text { therapy }\end{array}$} & \multicolumn{2}{|c|}{ LTME $\mathbf{n = 3 5}$} & \multicolumn{2}{|c|}{ OTME $\mathbf{n = 4 9}$} & \multicolumn{2}{|c|}{ In total } \\
\cline { 2 - 7 } & $\begin{array}{c}\text { Abc. } \\
\text { number }\end{array}$ & $\%$ & $\begin{array}{c}\text { Abc. } \\
\text { number }\end{array}$ & $\%$ & $\begin{array}{c}\text { Abc. } \\
\text { number }\end{array}$ & $\%$ \\
\hline Total & 8 & 22.85 & 10 & 20.4 & 18 & 18.9 \\
\hline Partial & 27 & 77.14 & 39 & 79.59 & 66 & 69.47 \\
\hline
\end{tabular}

Table 4: Thedistribution of patients in the OTME and LTME groups depending on the complete or partial response to neoadjuvant therapy.

\begin{tabular}{|c|c|c|c|c|}
\hline \multirow{2}{*}{$\begin{array}{c}\text { Response to } \\
\text { Neoadjuvant therapy }\end{array}$} & \multicolumn{2}{|c|}{ LTME $\mathbf{n = 3 5}$} & \multicolumn{2}{c|}{ OTME $\mathbf{n = 4 9}$} \\
\cline { 2 - 5 } & Aбc.number & \% & A6c. umber & $\%$ \\
\hline HighRegression & 6 & 17.14 & 7 & 14.29 \\
\hline Satisfactoryregression & 9 & 25.71 & 14 & 28.57 \\
\hline Unsatisfactoryregression & 20 & 57.14 & 28 & 57.14 \\
\hline
\end{tabular}

Table 5: Criteria for evaluating the degree of regression of a tumor in colorectal cancer (Wheeler scale).

and veins, a paretic expansion of the lumen is noted: in the arterioles, plasma saturation is noted. Lymphohistiocytic perivascular infiltrates are noted (Figure 1).

During unsatisfactory regression, tumor cells retain their viability over a longer period. The noted dystrophic changes in tumor cells are at the level of mild protein dystrophy, manifested by the inconspicuous vacuolization of the cytoplasm, by the blurring of cell borders, by small deposits of cellular detritus in the lumen of adenocarcinoma complexes, and tumor cells also retain high invasive ability, since multiple lymphatic vessels are noted for multiple tumor emboli.

During satisfactory regression in the stroma, initial sclerotic changes develop, as well as marked lymphohistiocytic infiltration around the vessels. Dystrophic and necrobiotic changes develop in different tumor cells in the deep divisions of the neoplasm.

In this regard, the degree of regression was estimated by us very carefully. With a macroscopic visual examination of the material removed during the operation, it was found that as a result of preoperative radiotherapy in 11 cases the tumor completely dissolved, and in 7 , instead of tumor tissue, a small fibrous tissue was found. However, microscopic analysis showed that in these groups, a high degree of regression was found in $72.2 \%$, and satisfactory in $27.8 \%$. We found that microscopically, after neoadjuvant therapy, a reduction in the number of tumor cells and an increase in the number of fibrotic elements in the stromal tissue is characteristic. In the tumor cells, morphological changes such as mucinous metaplasia, fibrosis, calcification, and atypical fibroblasts in the stroma were detected.

Taking all this into account, we believe that the expectanttactics regarding those who gave a full response to neoadjuvanttherapy of patients are not appropriate. In our opinion, the correct removal from the point of view of prevention of relapses and metastasis is the complete removal of an intestinal fragment with carcinogenic potential. Tactics of waiting and observation can be used in patients with contraindications to surgical intervention (concomitant diseases, elderly patients, etc.), as well as in depleted patients.

\section{References}

1. Asimov EG (2017) Place of radiotherapy in complex treatment of rectal cancer Health 1: 33-39.

2. Julien LA, Thorson AG (2010) Current neoadjuvant strategies in rectal cancer Journal of Surgical Oncology 101: 321-326.

3. Muraviev AV, Volostnikov EV, Dontsov AE (2009) The role of MRT in the stage diagnosis and planning of treatment of rectal cancer / Mat. I congress of coloproctologists of the CIS. Tashkent, pp: 239-240.

4. Azimov EH (2017) Comparative studyng of circumferental resection margin in different methods of total mesorectal excision and their influence on the remote results of patients treatment. Scinces of Europe 1: 16-22.

5. Quirke P, Durdey P, Dixon MF, Williams NS (1986) Local recurrence of rectal adenocarcinoma due to inadequate surgical resection. Histopathological study of lateral tumansprcad and surgical excision. Lancet 2: 996-999.

6. Madoff RD (2004) Chemoradiotherapy for rectal cancer. When, why and how? N. Engl J. Med 351: 1790-1792.

7. Schrag D (2013) Evolving role of neoadjuvant therapy in rectal cancer. Curr Treat Options Oncol 14: 350-364.

8. Wheeler JM, Warren BF, Mortensen NM, Ekanyaka N, Kulacoglu H, et al (2002) Quantification of histologic regression of rectal cancer after irradiation. Diseases of the Colon \& Rectum 45: 1051-1056.

9. Azimov EG, Gadirova EM (2017) Pathohistological Assessment of the Circular MargiN oF Resection During Total Mesorectalexcision, Conductedon The Maliginant Formations of the Rectum. International Journal of Research Studies in Sience, Engineering and Technology 4: 17-22.

10. Overdevest JB, Theodorescu D, Lee JK (2009) Utilizing the molecular gateway: the path to personalized cancer management. Clin Chem 55: 684-697.

11. Berardi R, Maccaroni E, Onofri A, Giampieri R, Bittoni A, et al. (2009) Multidisciplinary treatment of locally advanced rectal cancer: A literature review. Espert. Opin Pharmacoter 10: 1-14.

12. Kalyan A, Rozelle S, Benson III A (2016) Neoadjuvant treatment of rectal cancer: where are we now?. Gastroenterology Report 4: 206-209. 